\title{
Role of iron oxides on physical protection of soil organic matter inside aggregates
}

\author{
LiXia Jin, PEgGy A. O’DAy, Asmeret AsEFAW \\ BERHE $^{1}$ \\ ${ }^{1}$ Environmental Systems Graduate Group, University of \\ California, Merced
}

Organic matter $(\mathrm{OM})$ and pedogenic iron $(\mathrm{Fe})$ are major binding agents that facilitate soil aggregate formation and stability. However, few studies have investigated how different forms of pedogenic $\mathrm{Fe}$ influence carbon (C) distribution in different sized aggregates. We sequentially extracted pedogenic $\mathrm{Fe}$ and determined the amount of $\mathrm{C}$ associated with macroaggregates (2000-250 $\mu \mathrm{m})$, microaggregates $(250-53 \mu \mathrm{m})$, and two silt and clay fractions (53-20 $\mu \mathrm{m}$, and $<20 \mu \mathrm{m})$ in an Alfisol from the Sierra Nevada mountains in California. Findings of our study revealed that sodium pyrophosphate (PP)-extracted $\mathrm{Fe}$ was the major pedogenic Fe pool associated with $\mathrm{C}$ in soils, especially in smaller soil aggregates. PP-extractable calcium (Ca) was strongly correlated with PP-extractable $\mathrm{Fe}$ and $\mathrm{C}$, possibly suggesting that both polyvalent cations $(\mathrm{Fe}$ and $\mathrm{Ca}$ ) contribute to $\mathrm{C}$ storage in the soil we studied. The concentration of hydroxylamine hydrochloride-extracted $\mathrm{Fe}$ (i.e., poorly crystalline Fe oxides) was consistently low, compared to PPextractable $\mathrm{Fe}$, but was higher in the largest soil aggregate size range of 250-2000 $\mu \mathrm{m}$. The proportion of PP-extracted Fe decreased, but that of dithionite hydrochloride-extracted Fe (i.e., crystalline Fe oxides) increased with increasing soil depths, likely due to the translocation of Fe oxides along soil profile through illuviation process, or because high concentration of organic matter in surface soils likely limits $\mathrm{Fe}$ crystallization. Our results show that pedogenic Fe plays important roles in preservation of OM inside soil aggregates. 